\title{
Artistic Characteristics, Visual Language and Expression Form of Wood Based on Design Field
}

\author{
Zhao Xu \\ Faculty of Design \\ Southwest Forestry University \\ Kunming, China 650224
}

\author{
Jing Guo \\ Faculty of Design \\ Southwest Forestry University \\ Kunming, China 650224
}

\begin{abstract}
Based on design science, this paper explains the artistic characteristics, visual language of wood together with the relationship between wood-based decorative art and its expression form from the perspective of aesthetics. Moreover, utilization principles and design concept for better expression are also discussed to help the designer applies wood scientifically, artistically and creatively according to a target object. This paper aims to provide a pluralistic theoretical support for the scientific development of human living environment design and explore developing trend of wood directive art to provide a reference for the design and research of human living environment.
\end{abstract}

Keywords-wood; artistic characteristics; vision language; expression form; decorative art; design science

\section{INTRODUCTION}

Wood, as the first element of traditional materials, makes up visualized objects in thousands of postures to provide comfortable and elegant environment for human beings. It also plays an important role in creating a certain style and entertaining atmosphere of the living environment. With the promotion of people's aesthetic awareness, more and more attention has been paid to wood, the important element of decorative art. As a result, wood is used not only for protective effect but as a part of diverse decorative art to keep up with the times to meet the demand of spiritual life apart from lifting living environment. In addition, the new function of wood adds more value to people's spiritual life by presenting its characteristics of design and the times.

\section{ARTISTIC CHARACTERISTICS OF WOOD}

According to archaeological discoveries and historical documents, wood contains profound spiritual intension and inner quality. Deng Chun lived in the Southern Song Dynasty ever said: "the whole world knows that a human has spirit, while no one know an object has spirit too". Ye Xie in Qin Dynasty wrote: "beautiful objects are everywhere, as beauty is the nature of an object" . Wood is considered as beautiful because it is integrated with the meaning and value formed during the long-term production, laboring and life, which shapes people's idea and imaginary of wood and reminds people of the image of beauty and arouse their reflection of beautiful and brings pleasure. The fully displayed beauty nature of wood is one of the important conditions for the integration, coordination, communication and conversation between human and environment, that is, "unity of heaven and man".

As a kind of biological materials, wood is produced by living things and has a complete cycle-from towering trees to $\log$, lumber, veneer and to humus in the end. In addition, it is also a witness of time variation by changing its expression form and adding imprints in the surface as time goes by. The meaning of life makes it distinguished from other materials. Therefore, the application of wood conforms to the ecology principle as well as contributing to people's mental health. In the world full of artificial works, wood provide people a chance to get close to the nature. The form of the wood varies all the time, but its spirit never changes, leaving people a sense of history and inheritance.

Wood is a valuable natural resource, abundant with human touch. It gives the sense of nature, warmness, comfort, grace, freshness, cheer and elegance, showing a kind of simple and unadorned natural beauty. These artistic characteristics of wood make it capable of creating unique decorative effects. Due to the strong affinity and sense of belonging it brings, wood has become the material closest to people's life. Hence, it is right to reveal and highlight the natural beauty of wood when using it, especially through the combination between the natural color and texture of wood and the strong texture of ashlars or slabstones. The comparison makes a further accentuation of the natural, warm and simple and plain quality to integrate into the living ambience of human being.

\section{VISUAL LANGUAGE OF WOOD}

Wood is one of the earliest materials used by humans and also one of the mostly applied materials in their living environment. The wood-based decorative art comes from life and modern decoration has increasingly paid attentions to the language expression of wood. Wright ever said: each material has its own language... each material has its own story. For those creative artists, each material has its own faith and songs. The utilization of wood is closely associated with art, otherwise it is likely to lose its soul. Hence, an excellent artistic design has to be the one that gives a full consideration of the original characteristics of wood to reveal its natural beauty, and this is also the call of people expecting to return to nature. The aesthetic attribute of wood is conveyed to people through vision and touch and for a designer, his ability to mine, 
acknowledge and apply this beauty attribute of wood is directly related to the art level and use value of a decorated entity.

\section{A. Texture language}

Texture is the organizational structure and one of the natural attributes of wood. Different textures give people different senses of vision, touch and psychology, for example, wood gives a sense of softness, hardness, tenaciousness and warmness. Likely, different materials have different textures, and thus although texture characteristics of wood can be altered through various ways such as machining and artificial synthesis, there is no technology to complete the natural generation process of wood artificially. Therefore, in the creation of human living environment, it is important to understand the meaning of texture to minimize its disadvantages by making full use of its advantages. Additionally, due to diverse tree species, the textures of them are distinct showing in surface characteristics, and just because of this, various textures of wood are obtained, which are expected to create different psychological and decorative effects. It is typical of seeking, finding and mining the natural beauty of wood, as natural beauty is often more captivating artistically than floral designs.

\section{B. Color language}

As a saying goes, "appreciate flowers nearby; see colors afar", so color as an important design element of decorative art determines the basic decorative style, likely to stir up people's feelings of all kinds. Moreover, the different light absorption and reflection effects of organic compounds in the wood cell make wood present with distinctive colors. Some wood with wonderful colors are popular with people, for example, maple wood that is light yellow white, quietly elegant and bright; teak wood which is yellowish-brown, simple and dignified; mahogany which is red brown, gorgeous and exalted; black walnut that is black brown, deep and dignified. As one of key characters of color language, color is an important reference to recognize tree species and to determine the impression of wood. In addition, wood of the same variety has varies colors. In general, color is perceived through people's subjective visual perception and described with the help of words, such as dragon spruce white as snow; milk-white poplar; light grey brown basswood; red brown beech, light brown ashtree; red brown santos rose wood; dark ebony.

Wood is the carrier of color, and color attaches to wood, and hence the beauty nature and natural appearance shall be fully used to enrich the expressive force of artistic work. Different colors of wood leave people with different impression and psychological feelings. For example, wood with high brightness gives people the mental impression of liveliness, neatness and showiness, while wood with lower lightness makes a mental impression of gorgeousness, deepness and earnest. Color as an important part of human living environment has an influence on its overall effect, so color has to be employed scientifically, artistically and creatively and integrated with the personality, habits, interests and life style, etc. For instance, in wood-based decoration, light-colored wood shall be selected to create a delicate tone, and darkcolored wood for a warm tone.

\section{Texture language}

Texture is formed due to the different alignment of longitudinally orientated wood cells and is an important element to form patterns having high value in decorative art. By sawing the wood from different directions, texture of various styles are expected to be attained. Generally, observation and study of wood focus on three typical sections: transverse section, radial section and tangential section. Thereinto, in the transverse section, the annual rings consist of many concentric circles that are thick or thin, dark-colored or light-colored, making people feel dynamic, fresh and cheerful; in the radial section, the annual rings are parallel strips; in the tangential section, the annual rings are in a shape of waved parabolas or mountains, giving a sense of elegance, smoothness and easiness. There are great differences among structures of wood cells, that is, textures of wood from disparate varieties are diverse in the distribution of thickness and the clearness, but this is in favor of the integration of human, wood and the environment. Besides, texture makes wood seemingly more natural, amiable, elegant and moderate. For example, cherry with straight and fluent textures gives people a sense of firmness and strength as well as courage; fraxinus mandshurica with most curve textures that make up circles, ovals or irregular figures, leaving people with a sense of grace, charm, gentle and thoughtfulness.

Texture is one of the design characteristics of wood, its alignment has a great influence on the decorative art. For some wood from some tree species, their characteristics are un-sharp, such as coniferous wood often with straight and even texture, which has a poor decorative effect and is better used for plain decoration, and such kind of wood includes pinewood, cedarwood, etc; some other wood has natural texture, for example, thick-porous wood of broad-leaved wood has texture with staggered thickness, bright and pleasant color, showing dynamic esthetics and looking vivacious artistic and clear, such as camphorwood, teakwood and rosewood, while thin-porous wood of broad-leaved wood has delicate and uniform texture together with peculiar color, showing a silky and silk paintinglike static beauty, such as briar wood and basswood.

\section{Theme language}

Patterns are the distinct stripes or streaks in wood surface, which are formed under the combined factors of color, texture, annual rings, knots and sawing direction, etc. Thereinto, there are two key aspects: patterns made up by almost parallel but uncrossed textures, giving people a sense of smoothness, neatness and easiness; patterns influenced by time, climate, site conditions etc. bring about different variation in different parts, leaving a sense of levity, fluctuation, movement and life. These wood patterns have recorded the feelings of wood when it communicates with nature and are the beautiful gifts nature gives to humans, reflecting the aesthetics law of change and unity of style design, so these patterns are easy to be accepted without getting bored even through long period. In addition, texture is closely associated with the volume variation and patterns with the surface. These patterns generate naturally or artificially, and thereinto natural patterns are reaching the acme of perfection while these artificial ones are also extraordinary wonderful. Natural patterns or artificial ones have their own 
specific requirements. Obvious shadings are adopted to highlight the texture and dark shadings to express an implied meaning so as to achieve a better decorative art effect. Using natural wood patterns is the forever theme as for the decorative art, as they are likely to create a plain, simple, elegant and moderate living environment for humans and attract people to appreciate these works of art. In this way these natural patterns play an important role in improving the spatial relationship of people and wood and the communication with each other at short range.

Designs are artificially depicted or processed pictures that are made up of colors, lines and figures and most of them reveal the original and unique aesthetics combining decorative art and folk art, which can be concrete or abstract, colorful or colorless, with or without a theme. According to different occasions, people select various design elements such as geometric figures, images of flowers and plants, insects and fish, birds and animals, natural and artificial landscapes along with characters to express their cultural values and artistic pursuit such as tradition, worship, totem and belief, directly reflecting the folk traditional culture and also an important element of decorative art to improve the cultural atmosphere of human living environment.

\section{EXPRESSION FORM OF WOOD BASED ON DESIGN FIELD}

Wood has physical property that is expressed using modern technologies in different forms, and this is the outward manifestation of wood. The outward manifestation has a psychological influence on people through influencing the style of their living environment and this kind of influence is a reflection of its inner nature. In this way, the coexistence of outward manifestation and inner nature of wood exerts an influence on people's vision and mind. People with disparate personalities are expected to love different wood and this is the expression function of wood. The expression of wood conveys the aesthetic pursuit and art taste of a designer, and in terms of this, wood is not the wood with original meaning for the designer, but the one branded with specific affections. In this way, wood is closely connected with the design ideas and the considerations, and becomes one of the sign expressing feelings precisely.

Based on the design field, the selection of wood and application of its expression form come down to the re-creation of wood. Abundant expression forms of wood provide adequate conditions for design ideas, which is an important link in expressing individualized language in the decorative art. The diversity of wood is likely to spark active imagination and creative inspiration of the designer who is able to choose proper range of structure manifestation. Once a certain kind of wood is selected, it's the time to consider which manifestation way is better to create a specific human environment. Therefore, the course of wood processing, combination and alteration is a sublimating process of art creation, orchestration of art symbol to become more vigorous and also development process of human living environment to the maximum degree.

\section{A. Paint decoration}

It has been a long time since people have used paint to cover wood, and they have accumulated abundant experience in paint decoration, and enriched splendid Chinese culture. By means of the long history, specific style and exquisite craftsmanship, paint art is a kind of precious Chinese culture wealth, which is shining with brilliance in Chinese ancient civilization development history. Oil painting is actually a kind of art, and wood is of different styles. As a result, in wood decoration using paint, it is right to take into account of the appearance and inner quality worthy of special processing of the wood, apart from the decorative art effects produced by the combination of wood and other coating materials. If the wood has textures that are uniformly distributed and extend greatly, then it shall be decorated with varnish through which wood grain can be clearly seen to promote color contrast to create a sense of floating, splendor, quiet and calmness; if the wood has disorganized textures, it is better to be decorated with nontransparent paint with various colors and high quality. The colors include peach, bright red, brownish yellow, golden yellow, lilac, bright green, light blue, sea blue, silvery grey, camel gray, etc. and the quality involves glaze, granulation surface, etc. overall, the functionality and individuation of paint can meets selection requirements of people at different age group and also a key point to achieve the design effect for designers.

\section{B. Simulation decoration}

Since long time ago, skillful craftsmen have been beautifying wood through imaginative simulation decoration, and this kind of craft, always attractive and fascinating, is adopted to cover or exaggerate design details such as painting, dyeing and veneering. The combination of artistic characteristics of wood and simulation decoration can fully reveal the breathtaking beauty of natural wood and greatly highlight its art expressive force, creating a comfortable and amiable atmosphere and exhibiting the natural and plain style of wood. In this way, it is expected to improve the artistic beauty and use value of wood.

\section{Artistic decoration}

General aesthetic principle can be used in artistic processing of wood, and guides the style design of wood. For a long time ago, people had integrated many of wood characteristics into the local social civilization such as people's worship to wood carved totem. Essentially, wood products are practical works of art, so the processing methods of wood are generated during long-term production practice and used by designers. In addition, with high plasticity, wood can be modified through designing various decorative styles and patterns, or through painting, carving, inlaying, branding, jointing, appliquéing to reach the acme of perfection and fully reveal the harmony of artificial and natural work. There are many methods for artistic decoration, including coating (colored drawing, lacquer painting, etc.), caving (openwork carving, circular engravure, relief, etc.), inlaying (with shells, gold, etc), pyrograph, veneer parquet (applique, embossing, appliqué, etc.), decorating with gold and silver (gilding, gold drawing etc.), etc.. 


\section{CONCLUSION}

A great many design examples shows from all aspects that there is still lots of unknown in wood waiting for people to exploit. Based on design field, in terms of wood decorative, apart from functions, the wood selected has to meet people's aesthetic needs exhibiting its artistic characteristics. In addition, decorative art effects shall be selected in accordance with the harmony principles of texture and a designer should have the ability to skillfully exert the characteristics of wood by means of his keen feeling and rich creativity to visual language of wood to create a perfect expression form. Therefore, an excellent designer is expected to have a good command of the artistic characteristics, visual language, and expression form of wood to explore the natural beauty of wood material and texture centering on the design theme on the basis of aesthetic principles and the knowledge of decorative surfaces to fully exert the inner quality of the wood. Besides, it is a significant method to integrate wood expression and artistic imagination to express the design idea. As a result, based on the combination of theory and practice, designers are expected to find out a design law that can help to fully reveal the beauty of wood and explore an expression method that can combine the design law and idea so as to inject new vitality to human living environment.

\section{REFERENCES}

[1] Li Jian. New Guide of Wood Science [M]. Harbin: Northeast Forestry University Press, 1991.

[2] Li Jian, Zhao Rongjun. Wood and environment [M]. Harbin: Northeast Forestry University Press, 2001.

[3] Li Zehou. Chinese Aesthetics [M]. Tianji: Tianjin social science press, 2002.

[4] Tang Xingming. Decorative Art Design [M]. Chongqing: Chongqing University Press, 2005.

[5] Wang Zhuzhen, Chen Yaoming. Artistic Expression of Comprehensive Material [M]. Shanghai: Shanghai University Press, 2005.

[6] David Brett. Rethinking Decoration: Pleasure and Ideology in the Visual Arts [M]. Nanjing: Jiangsu Fine Arts Publisher. 